\title{
Perancangan dan Realisasi Sistem Monitoring Pulsa Minimum dan Pemberitahuan Kerusakan Pada KWh Meter Prabayar
}

\author{
Firmansyah Jeneldi ${ }^{1}$, Harlianto Tanudjaja ${ }^{2}$ dan Suraidi ${ }^{1}$
}

\begin{abstract}
Electricity is the energy needed for human life. The dominant human needs for using electronics, lighting and running the machine make the electricity has an important thing. All of them makes electricity must be supplied so that the tools can work. Many of electronics used to make electricity credit on kWh meter prepaid will quickly run out. The impact of power loss that happens repeatedly because depletion of electricity credit makes electronics has short life, this is often happens because the user cannot monitor $k W h$ meter prepaid. In this project, system can also monitor the status of electricity credit, abnormal incident and the estimated time of electricity credits running out. This system uses 3 photodiode sensors. It's for detecting pulse status when the pulse is at a minimum condition of $10 \mathrm{kWh}$, detecting an abnormal incident in case of damage or problems and detection estimated pulse depletion time to find out how long the electrical electricity credit has run out. This system is designed to detect the change of $k W h$ status from the indicator LED at $k W h$ meter. The receive data will be processed to determine the condition of the remaining pulse or $k W h$ meter state. The Controller of this system uses microcontroller which receive data from sensor. This system successfully displays data on LCD and LED indicator and can send data to user number via SMS when entering the minimum limit, while the pulse at 7, 4 and $1 \mathrm{kWh}$ and gives the estimated timeout of deplection pulse. With this monitoring system created is expected to reduce anxiety about the depletion of electricity pulse when leaving the machine or electronic who always standby without supervision
\end{abstract}

KEYWORDS: electrical detector, depletion of electricity, microcontroller, monitor, SMS.

\begin{abstract}
ABSTRAK : Listrik adalah energi yang dibutuhkan bagi kehidupan manusia pada zaman modern ini. Kebutuhan manusia yang dominan dalam menggunakan elektronik, penerangan dan menjalankan mesin membuat listik mempunyai peranan penting. Kebutuhan tersebut membuat listrik harus tetap bisa tersuplai sehingga alat-alat tersebut dapat bekerja. Banyaknya alat elektronik yang digunakan membuat pulsa pada kWh meter prabayar akan cepat habis. Dampak dari matinya listrik akibat habisnya pulsa listrik secara terus menerus dapat membuat alat elektronik tersebut rentan rusak, hal ini sering terjadi akibat pengguna tidak bisa memonitoring kWh meter prabayar tersebut. Dalam perancangan ini, sistem dapat memonitoring status pulsa, peristiwa abnormal dan estimasi waktu habisnya pulsa. Sistem ini menggunakan 3 sensor photodiode yaitu untuk mendeteksi status pulsa apabila pulsa berada pada kondisi minimum yaitu $10 \mathrm{kWh}$, peristiwa abnormal apabila terjadi kerusakan atau masalah dan estimasi waktu habisnya pulsa untuk mengetahui berapa lama waktu habisnya pulsa listrik. Sistem ini dirancang untuk mendeteksi Perubahan status LED indikator pada kWh meter. Pengendalian sistem dilakukan dengan menggunakan mikrokontroler yang menerima data dari sensor. Data yang diterima akan diproses untuk menentukan kondisi dari sisa pulsa atau keadaan $\mathrm{kWh}$ meter. Sistem yang dibuat ini berhasil menampilkan data pada LCD dan LED indikator serta dapat mengirimkan data ke nomor pengguna melalui SMS pada saat kondisi memasuki batas minimun, saat sisa pulsa berada pada 7, 4 dan $1 \mathrm{kWh}$ dan memberikan estimasi waktu habisnya pulsa. Sistem yang dibuat ini diharapkan dapat mengurangi rasa khawatir akibat matinya alat elektronik mesin dikarenakan pulsa habis saat ditinggalkan oleh pengguna.
\end{abstract}

KATA KUNCI : mikrokontroler, pantau, pendeteksi listrik, pulsa habis, SMS.

\section{PENDAHULUAN}

$\mathrm{L}$ istrik adalah energi yang dibutuhkan bagi kehidupan manusia pada zaman modern ini. Listrik berfungsi sebagai sumber energi yang dibutuhkan elektronik atau mesin untuk bisa bekerja atau bergerak. Kebutuhan listrik dominan digunakan pada beberapa bidang seperti perindustrian untuk menjalankan mesin, penerangan untuk menghidupkan lampu dan perumahan untuk menggunakan alat elektronik sebagai alat yang mempermudah dalam melakukan kegiatan sehari-hari, di mana asupan energi listrik di Indonesia berasal dari Perusahaan Listrik Negara (PT. PLN). PT.PLN Persero adalah perusahaan yang bergerak dalam bidang kelistrikan di Indonesia. PT.PLN Persero selalu memberikan pelayanan terbaik terhadap pelanggan pengguna listrik, sebelumnya PT.PLN masih menggunakan pelayanan konsumsi listrik menggunakan sistem pascabayar. Sistem pengguan listrik pascabayar bisa digunakan langsung dengan membayar tagihan setelah melakukan pemakaian pada akhir bulan. Transportasi, segi waktu, Pencatatan meteran ini menjadi kelemahan bagi pengguna listrik khususnya daerah terpencil dalam memprediksi frekuesi biaya listrik [3]. PT.PLN sudah mengatasi masalah tersebut dengan membuat pelayanan listrik pintar yang bertujuan untuk kepuasan pengguna, PT.PLN merubah sistem yang digunakan yaitu dari sistem pascabayar menjadi Sistem prabayar. Sistem prabayar yaitu pengelolaan konsumsi listrik melalui meteran elektronik dan menggunakan pulsa untuk mengaktifkan meteran listrik prabayar.

Listrik pintar yang menggunakan sistem prabayar ini memiliki beberapa keuntungan seperti: pelanggan dapat mengontrol penggunaan listrik sesuai kemampuan, privasi tidak terganggu, tidak ada sanksi pemutusan, pelanggan tidak lagi berurusan dengan pencatatan meteran dan jadwal pembayaran setiap bulan [1]. Hal tersebut yang membuat pengguna lebih Namun ada beberapa kekurangan seperti tidak ada pemberitahuan secara real time kepada pengguna yang tidak berada dirumah ataupun yang mempunyai $\mathrm{kWh}$ meter yang ditempatkan cukup jauh dari rumah seperti di garasi ataupun gudang sehingga indikator tidak bisa terlihat atau terdengar, apabila hal itu terjadi pengguna tidak bisa mendapatkan informasi mengenai kerusakan dan peristiwa abnormal pada $\mathrm{kWh}$ meter sedangkan ketika peristiwa itu terjadi maka akan terjadi error, hal ini berdampak listrik akan terputus, tidak ada pemberitahuan mengenai sisa pulsa dan tidak ada pemberitahuan estimasi waktu ketika pulsa berada pada saldo minimum $(10 \mathrm{kWh})$ sehingga pengguna tidak mengetahui sisa pulsa dan waktu yang tersisa dari kondisi minimum.

\footnotetext{
${ }^{1}$ Program Studi Teknik Elektro, Fakultas Teknik, Universitas Tarumanagara

2 Jurusan Teknik Elektro Universitas Katolik Indonesia Atmajaya
} 


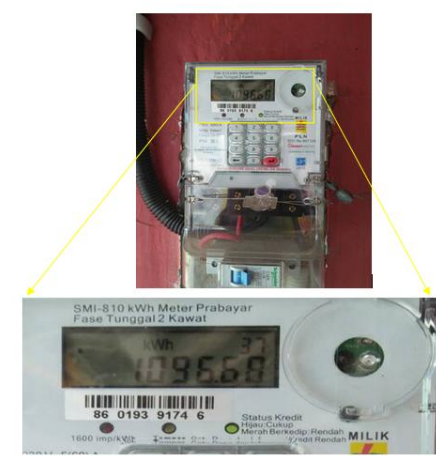

A

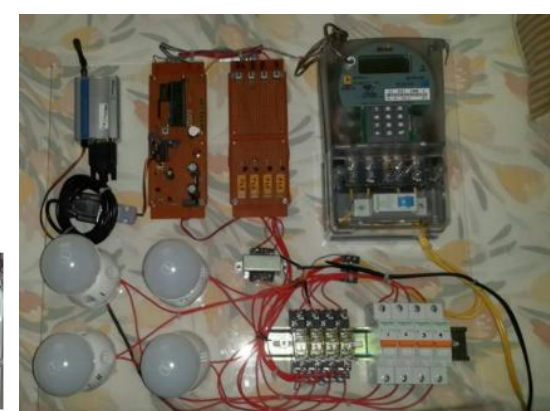

B

- Gambar 1 A. kWh Meter Prabayar Hasil Survei Pertama

B. Perancangan kWh Meter Digital Prabayar Survei Kedua

Survei yang dilakukan ini bertujuan untuk mengetahui cara kerja dan membandingkan sistem kWh meter prabayar yang biasa digunakan banyak orang ataupun alat yang sudah ada dibuat. Survei dilakukan sebanyak dua kali. Survei pertama kali dilakukan pada tanggal 26 Oktober 2016 pada perumahan PERUMNAS 1 kota Tangerang, Banten. Berikut adalah tampilan dari kWh meter bisa dilihat pada Gambar 1A. Terlihat kWh meter ini memiliki tiga Light Emitted Diode (LED) dan sebuah alarm yang digunakan untuk memberi peringatan kepada pengguna.

LED kedua yang bertuliskan temper ini berfungsi untuk menandakan bahwa terjadi peristiwa abnormal, peristiwa abnormal yang sering terjadi dikarenakan error atau percobaan untuk membongkar $\mathrm{kWh}$ meter, LED ketiga yang bertuliskan $1600 \mathrm{imp} / \mathrm{kWh}$ berfungsi untuk menandakan habisnya pulsa per $\mathrm{kWh}$, pulsa $1 \mathrm{kWh}=1600$ kali kedip[2].

Survei kedua pada tanggal 31 Oktober 2016 yaitu tugas akhir Universitas Tarumanagara Jakarta oleh Kevin dengan Nomor Induk Mahasiswa (NIM) 525110008 yang berjudul "Perancangan dan Realisasi Sistem Peringatan Sisa Pulsa pada kWh Meter Digital Prabayar" Survei ini dilakukan untuk mengetahui cara kerja sistem pada alat tersebut yang menggunakan modul mikrokontroler, modul detektor, modul catu daya, modul switch driver, modul Global System for Mobile Communication (GSM). Cara kerja alat ini menggunakan sensor photodiode yang diarahkan menuju indikator habisnya pulsa yang berupa LED merah, kedipan LED menandakan token pulsa akan segera habis, kedipan tersebut adalah data yang digunakan untuk mengetahui sisa pulsa pada $\mathrm{kWh}$ meter pada kondisi minimum, pada saat LED merah menyala juga terjadi aktivasi dari sistem otomatis pemadaman saklar Mini Circuit Breaker (MCB) sementara dan sistem pemberitahuan kepada pengguna melalui modul GSM berupa Short Message Service (SMS) pada interval yang sudah ditentukan oleh pengguna. Pemadam saklar MCB otomatis berfungsi untuk menghambat proses pemadaman total dan memberi tambahan waktu untuk melakukan pengisian ulang pulsa pada kWh meter. Data yang didapat dari LED merah tadi yang akan digunakan untuk menjalankan sistem otomatis pemadaman MCB dan pemberitahuan melalui SMS kepada para pengguna. Berikut adalah tampilan perancangan $\mathrm{kWh}$ meter digital prabayar survei kedua pada Gambar 1B.

\section{KAJIAN PUSTAKA}

Perancangan yang dibuat pada penelitian ini mengenai sistem monitoring pulsa minimum dan pemberitahuan kerusakan pada $\mathrm{kWh}$ meter prabayar dengan menggunakan modul GSM sebagai media dalam proses monitoring $\mathrm{kWh}$ meter kepada pengguna. Sistem ini dirancang untuk memperbarui sistem yang sudah ada menjadi lebih baik lagi. Sistem ini menggunakan fitur peringatan yang sudah ada pada $\mathrm{kWh}$ meter berupa LED yang terbagi menjadi tiga jenis LED pertama yaitu kredit yang menandakan pulsa harus diisi atau tidak, pada LED kredit ini memiliki dua warna yaitu hijau dan merah, warna hijau melambangkan pulsa berada pada kondisi pulsa diatas minimum dan tidak diharuskan untuk mengisi pulsa, sedangkan warna merah melambangkan pulsa berada pada kondisi minimum $(10 \mathrm{kWh})$ dan diharuskan untuk mengisi pulsa, pada kondisi ini LED merah berkedipkedip. LED kedua yaitu temper yang menandakan kondisi kWh meter error atau terjadi peristiwa abnormal apabila terjadi hal tersebut maka LED temper ini akan menyala berwarna kuning dan $\mathrm{kWh}$ meter akan terputus sehingga tidak dapat memberikan listrik kepada pengguna. LED ketiga yaitu $1600 \mathrm{imp} / \mathrm{kWh}$ yang menandakan turunnya pulsa $1 \mathrm{kWh}$ dengan memberikan 1600 kali kedipan pada LED tersebut. Agar mempermudah pembacaan dimisalkan, LED status kredit $=$ LED 1, LED temper $=$ LED 2 dan LED $1600 \mathrm{imp} / \mathrm{kWh}=$ LED 3. Alat rancangan yang digunakan akan melakukan pendeteksian pada $\mathrm{kWh}$ meter yang disimulasikan, kerja sistem $\mathrm{kWh}$ simulasi sama dengan yang asli hanya saja beban dibuat dengan memprogram $\mathrm{kWh}$ meter yang dipresentasikan sebagai beban penguji dengan besaran $3 \mathrm{kWh}, 6 \mathrm{kWh}$ dan $9 \mathrm{kWh}$. Perubahan-perubahan yang terjadi pada indikator LED ini yang akan digunakan oleh sensor cahaya sebagai data untuk memberikan informasi kepada pengguna. Pada sistem ini sensor cahaya pertama kali mendeteksi indikator LED 2 yang berwarna kuning untuk mengetahui 
keadaan dari kWh meter, ketika terjadi kerusakan LED kuning akan menyala dan sensor cahaya akan menangkap sinyal dan mengirimkan sinyal kedalam modul mikrokontroler. Modul mikrokontroler ini akan mengaktifkan modul GSM yang berfungsi mengirimkan informasi berupa SMS mengenai peristiwa abnormal kepada pengguna. Apabila LED temper tidak menyala maka sensor cahaya akan akan melakukan proses kedua yaitu mendeteksi indikator LED 1 yang berwarna hijau dan merah, ketika LED berwana hijau maka sensor akan mendeteksi pulsa pada $\mathrm{kWh}$ meter masih diatas minimum dan tidak melakukan proses apapun tetapi ketika LED berubah menjadi warna merah (kondisi minimum $10 \mathrm{kWh}$ ) maka sensor cahaya akan menangkap sinyal tersebut lalu akan mengirimkan sinyal ke dalam modul mikrokontroler. Modul mikrokontroler ini akan mengaktifkan modul GSM untuk mengirimkan informasi berupa SMS kepada pengguna mengenai pulsa berada pada kondisi minimum.

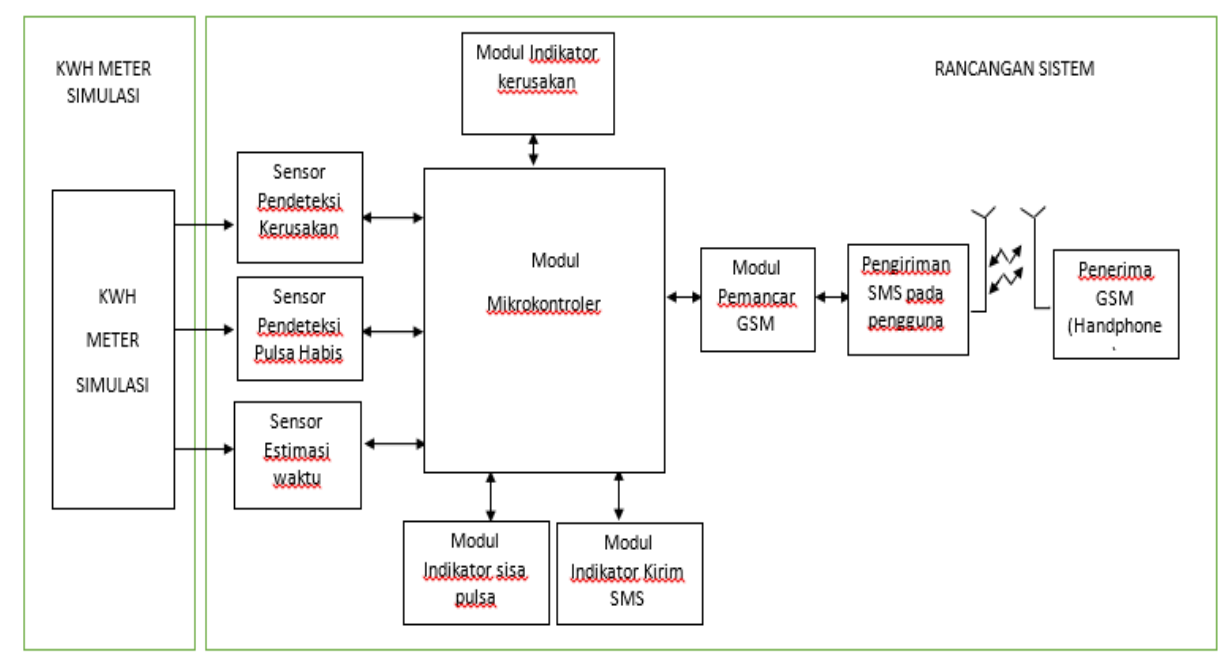

Gambar 2. Diagram Blok Perancangan Sistem Monitoring Pulsa kWh Meter

\section{DIAGRAM BLOK RANCANGAN}

Penelitian ini memiliki diagram blok sistem dapat terlihat seperti pada Gambar 2. Modul catu daya adalah sebuah rangkaian elektronik yang berfungsi sebagai sumber daya listrik untuk alat elektronik. Tegangan yang dihasilkan oleh catu daya bermacam-macam mulai dari $3,3 \mathrm{~V}, 5 \mathrm{~V}, 9 \mathrm{~V}$ sampai $12 \mathrm{~V}$ sesuai dengan kebutuhan dari rangkaian elektronik yang kita butuhkan. Catu daya yang tegangannya berasal dari PLN terhubung ke jala-jala listrik agar dapat terus memberikan daya listik ke rangkaian, catu daya ini memiliki sifat tidak portable yang artinya dapat berfungsi apabila terus terhubung pada jala-jala listrik. Tegangan yang kurang ataupun berlebihan dan tidak memenuhi spesifikasi rangkaian dapat merusak rangkaian elektronik oleh karena itu tegangan, arus dan lain lain dari catu daya harus dibuat sesuai dengan alat yang digunakan. Cara kerja dari catu daya itu sendiri yaitu pertama melakukan proses penerimaan tegangan masukan sebesar $220 \mathrm{~V}_{\mathrm{AC}}$ dari PT.PLN yang kemudian tegangan tersebut diturunkan dengan menggunakan transformator step-down. Hasil tegangan keluaran setelah dilakukannya step-down akan dimasukan pada proses tahap kedua yaitu penyearahan dengan menggunakan rectifier (diode penyearah) disini proses berubahnya tegangan Alternating Current (AC) menjadi tegangan DC. Ketika tegangan DC didapat maka menuju pada proses ketiga yaitu melakukan filter sinyal yang berfungsi sebagai penyaring frekuensi tegangan DC dan untuk meratakan gelombang yang terjadi dari proses rectifier sebelumnya, sedangkan regulator berfungsi agar tegangan keluaran dari catu daya tetap stabil, sehingga didapat nilai tegangan keluaran tidak mengalami perubahan yang signifikan dari nilai sebelumnya, Diagram blok rangkaian catu daya dapat dilihat pada Gambar 3.

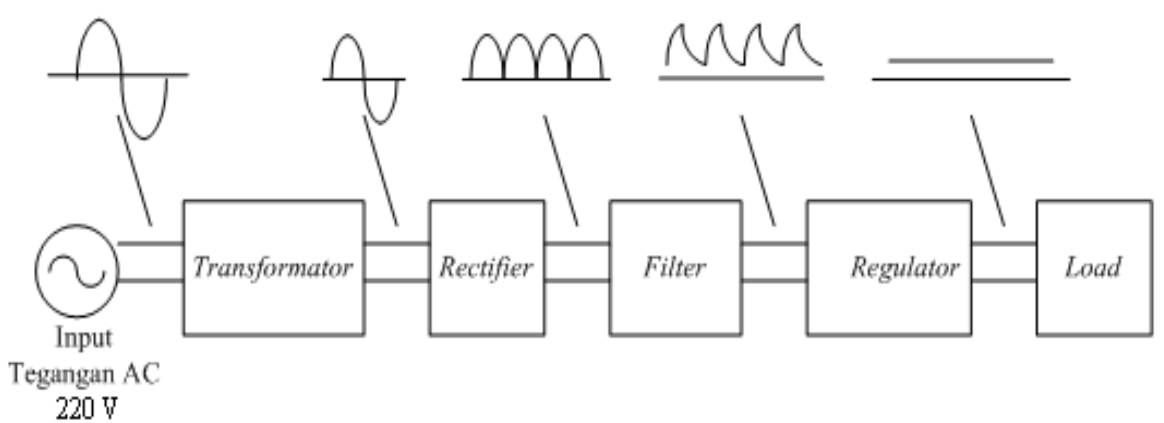

Gambar 3. Diagram Blok Catu Daya[4] 


\section{LIGHT EMITTED DIODE (LED)}

LED adalah komponen berfungsi sebagai penerang yang biasa digunakan sebagai penanda ataupun indikator pada kondisi tertentu. Penanda tersebut bisa berupa kedipan ataupun bentuk tulisan. LED ini digunakan sebagai tanda perubahan kondisi tersebut. LED yang digunakan berjumlah 3 yaitu berwarna yaitu hijau, kuning dan merah setiap LED ini memiliki arti ataupun tugas yang berbeda-beda. LED warna hijau menyala mengartikan mikrokontroler sedang melakukan proses pendeteksian $\mathrm{kWh}$ meter pada saat pulsa berada pada kondisi minimum, LED kuning menyala mengartikan mikrokontroler sedang melakukan proses pendeteksian $\mathrm{kWh}$ meter pada saat terjadi kondisi abnormal, LED merah menyala mengartikan mikrokontroler sedang melakukan proses pendeteksian modul GSM pada saat pengiriman SMS kepada nomor pengguna. Penggunaan LED ini agar pengguna bisa mengetahui dan mengamati segala proses kerja yang terjadi pada $\mathrm{kWh}$ meter, dimana LED ini diletakan pada output mikrokontroler pada bagian modul GSM dan sensor cahaya yang berfungsi untuk mendeteksi pulsa habis, peristiwa abnormal, estimasi habisnya pulsa pada LED 1, LED 2, LED 3. Selain sebagai penanda LED ini dapat mempermudah dalam mengetahui kerusakan atau kesalahan sistem pada alat. Seperti tidak terdeteksinya sinyal yang ditangkap oleh sensor terhadap perubahan LED pada kWh meter ataupun SMS yang tidak diterima oleh pengguna mengenai keadaan $\mathrm{kWh}$ meter. Ilustrasi Indikator LED ini dapat dilihat pada Gambar 4.

\section{MODUL MIKROKONTROLER}

Mikrokontroler adalah komputer mikro dalam satu chip tunggal, mikrokontroler ini berfungsi sebagai otak utama dari beberapa komponen pada modul mikrokontroler. Untuk membuat mikrokontroler diperlukan rangkaian minimum sistem. Rangkaian minimum sistem adalah sistem elektronika yang terdiri dari komponen-komponen dasar yang dibutuhkan oleh suatu mikrokontroler agar dapat berfungsi dengan baik [5]. Mikrokontroler biasanya digunakan dalam sistem-sistem yang dikendalikan secara otomatis Pada umumnya suatu mikrokontroler terdiri dari 3 bagian penting yaitu input/output, pemroses dan memory. Mikrokontroler merupakan suatu pengintegrasian antara sebuah Central Processing Unit (CPU) dengan memory dan perangkat input/output yang disertai dengan beberapa fungsi lainnya misalnya seperti timer, counter, dalam sebuah chip [6]. Untuk memberi gambaran mengenai apa saja yang ada didalam mikrokontroler dapat dilihat diagram blok mikrokontroler pada Gambar 5.

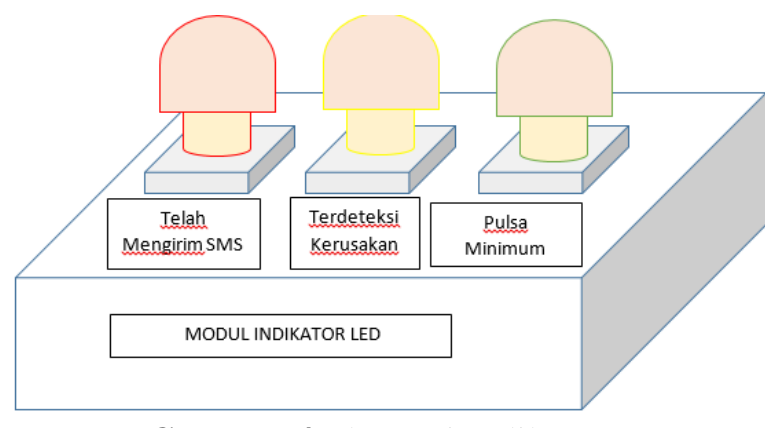

- Gambar 4. Ilustrasi Indikator LED

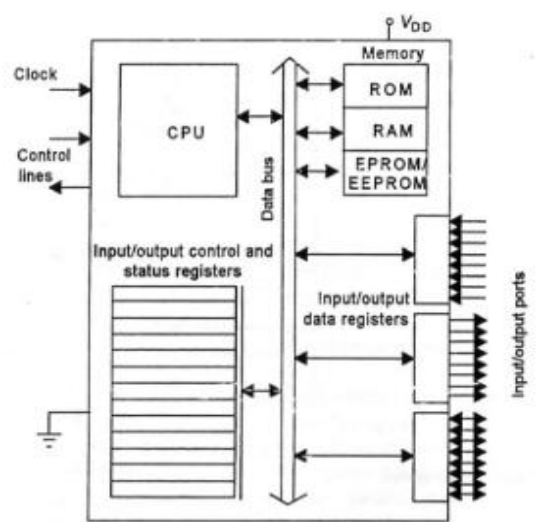

- Gambar 5. Diagram Blok Mikrokontroler[7].

Komponen-komponen mikrokontroler terdiri dari:

Central Processing Unit (CPU) adalah bagian mikrokontroler untuk menjalankan setiap instruksi dari setiap program. CPU juga berfungsi sebagai pengedali seluruh operasi pada mikrokontroler. Ada 2 bagian dari Unit CPU yaitu CU (Control Unit) dan ALU (Aritmetic logic Unit). CU berfungsi sebagai penerjemah susunan instruksi menjadi kumpulan proses kerja sederhana yang diambil dari memori lalu melakukan urutan instruksi sesuai dengan 
langkah-langkah yang telah ditentukan program sedangkan ALU bagian yang berhubungan dengan operasi aritmatika seperti penjumlahan, pengurangan, perkalian dan perbandingan.

Memori memiliki 3 bagian yaitu Random Access Memory (RAM), Read Only Memory (ROM), dan Eraseable and Programmable ROM (EPROM)/ Electrically Erasable PROM (EEPROM). RAM adalah media penyimpanan yang sifatnya sementara. Data pada RAM akan tetap tersimpan selama mikrokontroler menyala sedangkan penyimpanan yang sifatnya tetap adalah ROM. Data pada ROM tetap tersimpan meskipun mikrokontroler tidak menyala. EPROM digunakan untuk ROM yang dapat diprogram dan isinya dapat digantikan.

Input/output port pada mikrokontroler berfungsi sebagai penghubung dari mikrokontroler dengan alat elektronik lainnya. Dimana pada port input/output dapat diatur melalui program sehingga dapat ditentukan fungsinya port tesebut menjadi input/output. ATMega sendiri pada umunya mempunyai PORT utama yaitu PORT.B, PORT.C dan PORT.D dengan total pin I/O sebanyak 23 pin [7]. PORT tersebut dapat difungsikan sebagai I/O digital atau bisa juga sebagai alternatif lainnya. Program yang akan digunakan pada mikrokontroler ini salah satunya untuk pembacaaan ADC menggunakan photodiode yang bertujuan untuk menangkap sinyal sinyal yang diberikan dari indikator $\mathrm{kWh}$ untuk dideteksi perbedaan ADC dari kedua LED yang berada pada $\mathrm{kWh}$ meter dan bisa melakukan instruksi-instruksi selanjutnya. Berikut Gambar 6. Keterangan Pin Out Salah Satu Jenis ATMega.

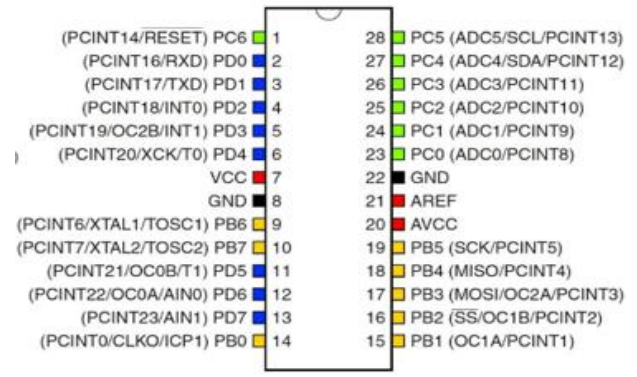

- Gambar 6. Keterangan Pin Out Salah Satu Jenis ATMega

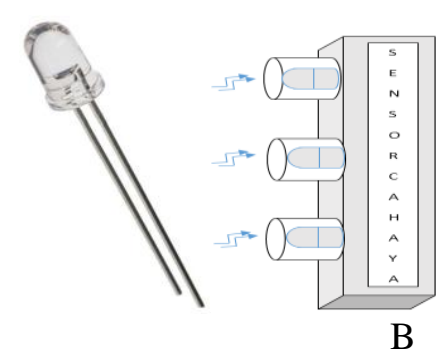

aGambar 7 A. Photodiode

B. Ilustrasi Modul Sensor Cahaya

\section{SENSOR CAHAYA}

Sensor cahaya adalah komponen yang sering digunakan untuk menghasilkan perubahan resistansi pada terminal output berdasarkan dari perubahan intensitas cahaya yang diterima. Sensor cahaya ada 3 jenis yaitu LDR (Light Dependent Resistor), photodiode, phototransistor. Secara garis besar bentuk fisik ketiga sensor cahaya ini memiliki perbedaan tetapi cara kerja dari tiga jenis sensor cahaya ini hampir sama yaitu ketika sensor ini menerima cahaya yang besar maka resistasi pada sensor tersebut akan mengecil sebaliknya ketika sensor cahaya ini mendapatkan sedikit cahaya maka resistasi pada sensor ini akan membesar. Sensor cahaya berfungsi untuk mendeteksi cahaya yang masuk dan kedalam photodiode, cahaya disini berasal dari indikator yang berupa LED pada kWh meter. Salah satu jenis sensor cahaya ini dapat dilihat pada Gambar 7A. Photodiode

Sensor cahaya yang digunakan pada modul ini sebanyak 3 buah yang digunakan untuk mendeteksi indikator LED yang berada di kWh meter. Cara kerja sensor cahaya sendiri mendeteksi perubahan yang terjadi dari LED pada $\mathrm{kWh}$ meter, dimana setiap perubahan warna LED memiliki nilai yang berbeda-beda, perbedaan nilai resistansi yang berubah-ubah yang didapat oleh sensor cahaya dari LED ini yang akan digunakan sebagai data yang akan dikirimkan menuju mikrokontroler untuk melakukan proses selanjutnya. Ilustrasi Modul Sensor Cahaya dapat dilihat pada Gambar 7B.

\section{GSM}

Global System for Mobile Communication atau biasa disebut dengan GSM adalah sebuah teknologi komunikasi seluler dengan menggunakan teknik digital secara wireless. GSM ini biasanya digunakan melalui handphone ataupun modem untuk melakukan SMS, menelpon ataupun internetan. Modem merupakan singkatan 
dari Modulator Demodulator. Modulator adalah suatu alat yang berfungsi untuk melakukan modulasi sinyal informasi menuju sinyal pembawa (carrier signal). Demodulator adalah alat yang berfungsi untuk melakukan demodulasi yaitu pengambilan kembali sinyal informasi yang telah termodulasi ke dalam sinyal pembawa. Modem merupakan gabungan dari kedua fungsi tersebut yang menjadikannya sebuah alat komunikasi dua arah.

Modem GSM adalah modem yang bekerja memodulasi dan mendemodulasi sinyal-sinyal dalam standar GSM. Modem GSM yang terkendalikan memungkinkan suatu user yang terhubung dengannya dapat melakukan SMS ataupun panggilan dari jarak jauh. modem GSM sudah banyak jenisnya dan sudah semakin lengkap dengan tambahan seperti Bluetooth dan radio FM (frekuensi modulasi). Modem GSM akan berfungsi dengan cara memerintkannya dengan menggunakan perintah AT command yang sudah disediakan untuk modem GSM, perintah tersebut bisa digunakan untuk mengirim pesan, melihat kekuatan sinyal dan menentukan format mode. Perintah AT Command dapat dilihat pada Tabel 1. Perintah AT Command. Salah satu contoh modul GSM dapat dilihat pada Gambar 8. Modul GSM
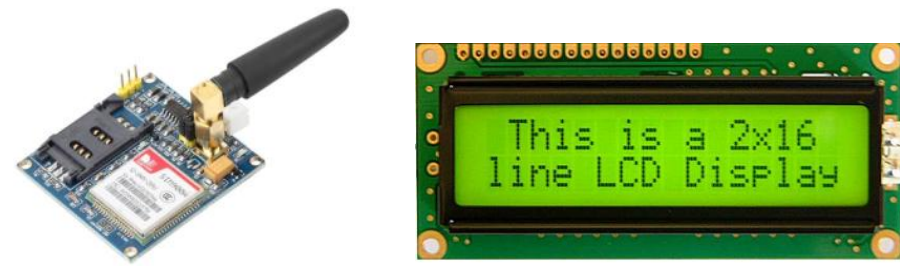

Gambar 8. Modul GSM (kiri) dan LCD Alfanumerik 2x16 (kanan)

Tabel 1. Perintah AT Command

AT Command

\begin{tabular}{|c|c|}
\hline AT Command & Keterangan \\
\hline AT & Mengecek apakah Handphone telah terhubung \\
\hline $\mathrm{AT}+\mathrm{CMGF}$ & Untuk menetapkan format mode dari terminal \\
\hline $\mathrm{AT}+\mathrm{CSCS}$ & Untuk menetapkan jenis encoding \\
\hline $\mathrm{AT}+\mathrm{CNMI}$ & $\begin{array}{l}\text { Untuk mendeteksi pesan SMS baru masuk secara } \\
\text { otomatis }\end{array}$ \\
\hline $\mathrm{AT}+\mathrm{CMGL}$ & Membuka daftar SMS yang ada pada SIM Card \\
\hline $\mathrm{AT}+\mathrm{CMGS}$ & Mengirim pesan SMS \\
\hline $\mathrm{AT}+\mathrm{CMGR}$ & Membaca pesan SMS \\
\hline $\mathrm{AT}+\mathrm{CMGD}$ & Menghapus pasan SMS \\
\hline $\mathrm{AT}+\mathrm{CGMI}$ & Mengecek Merek HP \\
\hline $\mathrm{AT}+\mathrm{CGMM}$ & Mengecek Seri HP \\
\hline $\mathrm{AT}+\mathrm{CGMR}$ & Mengecek Versi Keluaran HP \\
\hline AT + CSMINS & Pemberitahuan Kartu SIM masuk \\
\hline $\mathrm{AT}+\mathrm{CSQ}$ & Mengecek Kualitas Sinyal \\
\hline $\mathrm{AT}+\mathrm{CCLK} ?$ & Mengecek Jam (waktu) pada HP \\
\hline $\mathrm{AT}+\mathrm{CGSN}$ & Mengecek Nomor IMEI \\
\hline $\mathrm{AT}^{\wedge} \mathrm{SCID}$ & Mengecek ID SIM CARD \\
\hline $\mathrm{AT}+\mathrm{CGSN}$ & Mengecek Nomor IMEI \\
\hline $\mathrm{AT}+\mathrm{CLIP}=1$ & Menampilkan nomor telepon pemanggil \\
\hline
\end{tabular}

\section{LIQUID CRYSTAL DISPLAY (LCD)}

LCD merupakan singkatan dari Liquid Crystal Display, dimana LCD berfungsi sebagai media untuk menampilkan visual secara elektronik. LCD bekerja dengan memanfaatkan ciri-ciri cahaya pada kristal cair (liquid crystal). Kristal cair ini tidak dapat memancarkan cahaya sendiri sehingga menggunakan alat lain yang dapat memancarkan cahaya.

Ukuran LCD sangat beragam dari ukuran yang sangat besar seperti televisi sampai berukuran kecil $1 \times 4$. Jenis-jenis LCD pun beragam seperti LCD alfanumerik, LCD seven segment dan LCD RGB. Jenis-jenis LCD yang digunakan ditentukan sesuai dengan kebutuhan. 
LCD yang banyak digunakan pada pengembangan alat-alat elektronik adalah LCD alfanumerik. LCD alfanumerik dapat menampilkan huruf, angka dan juga beberapa simbol-simbol. Huruf, angka dan juga simbol ini dapat digunakan untuk menunjukan status atau suatu data. Gambar LCD alfanumerik dapat dilihat pada Gambar 8.

\section{HASIL PENGUJIAN DAN ANALISIS}

Bab ini akan membahas mengenai pengujian dan analisis modul-modul yang digunakan dalam perancangan alat ini. Pengujian dan analisis ini dilakukan dengan diuji per modul bertujuan untuk menunjukan dan memastikan kinerja setiap modulnya bekerja dengan baik. Modul-modul yang akan diuji yaitu;

- Modul Catu Daya

- Modul Mikrokontroler

- Modul Sensor Photodiode Pendeteksi Status Pulsa, Peristiwa Abnormal \& Estimasi Waktu Habisnya Pulsa

- Modul Indikator LED

- Modul LCD (Liquid Crystal Display)

- Modul GSM (Global System for mobile communication)

\section{HASIL PENGUJIAN DAN ANALISIS MODUL CATU DAYA}

Pengukuran pada modul catu daya ini bertujuan untuk mengetahui tegangan yang diberikan oleh catu daya dalam memenuhi setiap modul-modul dari alat keseluruhan sesuai dengan apa yang diperlukan. Selain itu juga mengetahui kemampuan modul catu daya dalam memenuhi tegangan setiap modul-modul yang digunakan dan daya alat ketika semua modul sudah terintegrasi dengan baik.

- Tabel 2. Hasil Pengujian Tegangan yang Diterima Sensor Photodiode.

\begin{tabular}{|c|c|c|}
\hline \multicolumn{2}{|c|}{ Intensitas cahaya LED } & $\begin{array}{c}\text { Output Tegangan }\left(\mathrm{V}_{\mathrm{DC}}\right) \\
\text { (Photodiode })\end{array}$ \\
\hline \multirow{2}{*}{$\begin{array}{c}\text { LED } 1 \\
\text { (Status Pulsa) }\end{array}$} & Hijau & 1,2207 \\
\hline & Merah & 0,1562 \\
\hline \multirow{2}{*}{$\begin{array}{c}\text { LED } 2 \\
\text { (Temper) }\end{array}$} & Kuning & 0,7324 \\
\hline & Mati & 0,1220 \\
\hline \multirow{2}{*}{$\begin{array}{c}\text { LED } 3 \\
\text { (1600 imp/kWh) }\end{array}$} & Merah & 0,1562 \\
\hline & Mati & 0,1220 \\
\hline
\end{tabular}

Pengujian tanpa beban dilakukan dengan cara menghubungkan catu daya ke PLN, kemudian mengukur keluaran dari catu daya dengan menggunakan multimeter yang dipasang pada output dari catudaya. Tegangan yang didapat dari output catu daya tanpa menggunakan beban yaitu sebesar $5 \mathrm{~V}_{\mathrm{DC}}$.

Modul catu daya yang digunakan pada alat yang dirancang ini memiliki tegangan keluaran $5 \mathrm{~V}_{\mathrm{DC}}$ dan mengeluarkan arus listrik maksimum 1 Ampere. Pengujian dilakukan dengan mengukur arus yang dikeluarkan ketika modul-modul dihidupkan dan diberikan tegangan $5 \mathrm{~V}_{\mathrm{DC}}$ catu daya. Dengan menggunakan keseluruhan beban maka arus listrik yang digunakan dapat diketahui yaitu sebesar $0,8 \mathrm{~A}$.

\section{HASIL PENGUJIAN DAN ANALISIS MODUL SENSOR PHOTODIODE PENDETEKSI STATUS PULSA, PERISTIWA ABNORMAL DAN ESTIMASI WAKTU HABISNYA PULSA}

Pengujian modul sensor photodiode ini dilakukan untuk mengetahui apakah modul sensor photodiode ini dapat bekerja dengan baik. Pengujian dilakukan dengan cara mengetahui kondisi saat sensor photodiode mendeteksi cahaya dengan menggunakan 3 warna LED yaitu warna Hijau, kuning, Merah, Dimana warna LED tersebut digunakan pada $\mathrm{kWh}$ meter. Pengujian ini dilakukan dengan membedakan nilai ADC pada photodiode dengan menggunakan bantuan mikrokontroler untuk membandingkan hasil tegangan yang diterima pada photodiode dari setiap warna LED yang diuji. Pengujian ini dilakukan pada setiap sensor photodiode yang ada pada alat yaitu berjumlah 3 buah. Hasil pengujian tegangan yang diterima sensor photodiode dapat dilihat pada Tabel 2.

Berdasarkan dari hasil pengujian yang dilakukan sensor photodiode terhadap ketiga warna LED, photodiode mengalami perubahan hambatan yang dikarenakan intesitas cahaya yang didapat dari setiap warna LED yang diuji berbeda-beda sehingga dari perubahan warna LED tersebut menghasilkan tahanan yang berbeda pula. Tahanan yang berbeda-beda membuat tegangan output berbeda-beda juga, perbedaan tegangan yang didapat pada photodiode tersebut yang akan dijadikan perbandingkan untuk membedakan status dari $\mathrm{kWh}$ meter. Pada 
pengujian modul sensor photodiode untuk mendeteksi: status pulsa, peristiwa abnormal dan estimasi waktu habisnya pulsa dapat dikatakan bekerja dengan baik.

\section{HASIL PENGUJIAN DAN ANALISIS MODUL INDIKATOR LED}

Pengujian modul ini dilakukan untuk melihat apakah modul ini dapat menampilkan warna LED sesuai dengan input yang diterima pada modul ini. Modul LED indikator ini terdiri dari 3 LED yang berwarna merah, kuning dan hijau. Pengujian dilakukan dengan menggunakan program yang memberikan output bit 1 dan 0 untuk input dari LED sesuai dengan tabel pada pengujian. Hasil pengujan modul indikator LED dilihat pada Tabel 3.

Berdasarkan hasil pengujian, modul indikator LED ketika diberi logika 1 LED merah kuning dan hijau menyala dan pada logika 0 LED akan mati berarti modul dapat bekerja dengan baik.

Tabel 3. Hasil Pengujian Modul Indikator LED.

\begin{tabular}{cccl}
\hline LED & Logika & Kondisi Lampu & \multicolumn{1}{c}{ Keterangan } \\
\cline { 2 - 4 } Merah & 1 & Menyala & Mengirimkan SMS \\
\hline \multirow{2}{*}{ Kuning } & 0 & Tidak Menyala & Tidak mengirimkan SMS \\
\cline { 2 - 4 } & 1 & Menyala & Terdeteksi peristiwa abnormal \\
\hline \multirow{2}{*}{ Hijau } & 0 & Tidak Menyala & Tidak terdeksi peristiwa abnormal \\
\cline { 2 - 4 } & 1 & Menyala & $\begin{array}{l}\text { Terdeteksi Pulsa berada pada posisi minimum }(10 \\
\text { kWh })\end{array}$ \\
\hline
\end{tabular}

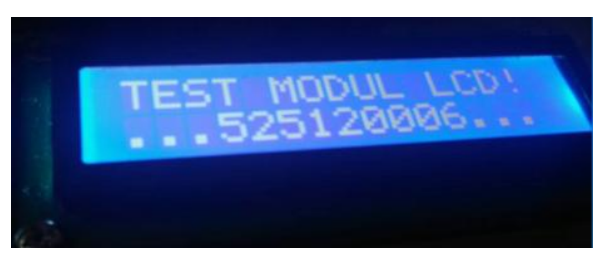

- Gambar 9. Pengujian Modul LCD

\section{HASIL PENGUJIAN DAN ANALISIS MODUL LCD}

Pengujian modul LCD bertujuan untuk memastikan bahwa modul LCD dapat menampilkan tampilan sesuai dengan tampilan yang diinginkan dan tidak terdapat kerusakan pada LCD. Pengujian ini dilakukan dengan memberikan program sederhana pada mikrokontroler untuk memberikan perintah menampilkan keluaran yang berupa teks "TEST MODUL LCD ...525120006..." pada layar LCD. dipilih karena mengingat LCD yang digunakan adalah LCD 16x2, maka karakter-karakter tersebut maksimum hanya bisa menampilkan sebanyak 32 karakter saja, pengujian modul LCD ini juga digunakan untuk memastikan agar LCD mampu menampilkan keluaran karakter yang sama sesuai dengan karakter masukan yang ingin ditampilkan.

Hasil Pengujian modul LCD dapat dilihat pada Gambar 9. yang menggambarkan hasil keluaran karakter dengan teks "TEST MODUL LCD! ...525120006..." Dari pengujian modul LCD yang dilakukan, keluaran dari LCD sesuai dengan perintah yang diberikan. Dengan ini, maka modul LCD dikatakan bekerja dengan baik.

\section{HASIL PENGUJIAN DAN ANALISIS MODUL GSM}

Pengujian modem GSM bertujuan untuk mengetahui apakah modem GSM yang digunakan dapat mengirimkan pesan singkat menggunakan perintah dari software UART susuai dengan yang diperintahkan oleh mikrokontroler. Pengujian dilakukan dengan membuat program sederhana yang memberikan perintah dalam format AT commands melalui software UART dan diperiksa apakah pesan terkirim dapat diterima oleh nomor GSM yang sudah ditentukan dari ponsel pengirim saat mengirimkan pesan.

Pengujian dilakukan dengan cara membuat program sederhana yang mengirimkan perintah. Perintah yang dikirimkan merupakan perintah untuk mengirimkan pesan singkat dengan isi pesan "Test Uji Modul GSM." Hasil dari pengujian berupa pesan singkat yang diterima sesuai dengan perintah yang diberikan dan proses pengiriman pesan ini juga dapat dilihat melalui serial monitor. Hasil yang dikeluarkan pada serial monitor berisi AT+CMGF yang memberi tahu user untuk mengatur mode SMS yang akan digunakan, 1 mengartikan menggunakan mode text sedangkan 0 mode PDU (Protocol Data Unit) dengan menggunakan heksadesimal, AT+CSQ memberi tahu user untuk masalah kekuatan sinyal, AT+CSMIN? memberi tahu pengguna apakah kartu telah terpasang dan AT+CMGS memberi tahu pengguna bahwa SMS telah dikirim. 
Berdasarkan hasil Pengujian modul GSM dapat dilihat pada Gambar 10 dan Gambar 11. Hasil tersebut menggambarkan keluaran yang berupa pengiriman SMS yang berupa teks "Test Uji Modul GSM." menuju kepada nomor pengguna "081290991017". Dari pengujian modul GSM yang dilakukan, keluaran dari Modul GSM sesuai dengan perintah yang diberikan. Dengan ini, maka modul GSM dikatakan bekerja dengan baik.

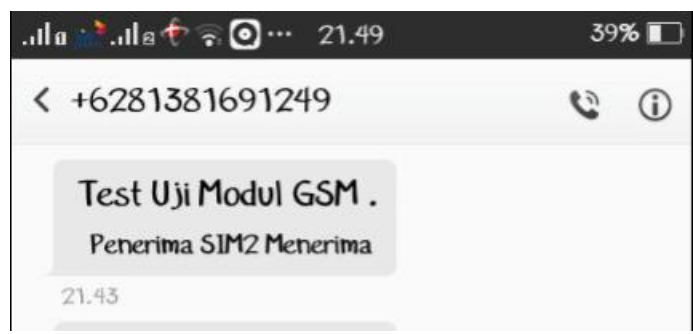

- Gambar 10. Pesan Singkat Hasil Pengujian Modem GSM

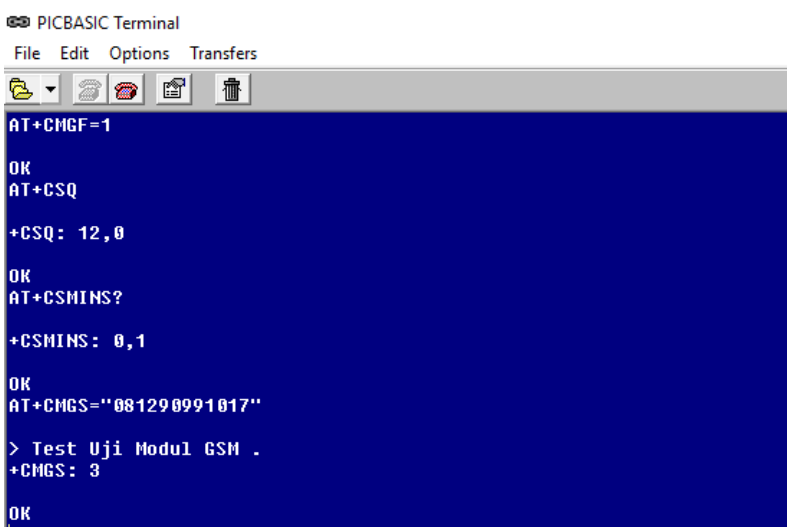

- Gambar 11. Proses Pengiriman Pesan Pada Serial Monitor GSM

\section{Hasil Pengujian dan Analisis Keseluruhan Sistem}

Pengujian keseluruhan sistem dilakukan dengan cara menguhubungkan keseluruhan modul, dari modul yang dirancang dan juga modul yang tidak dirancang. Pengujian yang dilakukan ini membuktikan apakah keseluruhan dari semua sistem dapat berjalan sesuai dengan fungsinya. Pengujian yang dilakukan pertama kali dilakukan dengan menguji sensor photodiode.

Pengujian pertama yaitu pada saat LED 1 menyala dan berganti warna dari hijau ke merah yang menandakan kondisi pulsa pada $\mathrm{kWh}$ listrik harus segera diisi, apabila sensor photodiode dapat mendeteksi intesitas cahaya dari perubahan LED dari setiap warna hijau dan merah dan dapat terbaca oleh photodiode dengan menggunakan ADC, ketika photodiode berhasil membaca maka mikrokontroler dapat memerintahkan modul GSM untuk mengirim SMS kepada pengguna mengenai pulsa kWh meter yang berada pada posisi batas minimum yaitu $10 \mathrm{kWh}$ meter, ketika semua proses tadi berjalan dengan lancar dan sesuai dengan yang diinginkan berarti pengujian ini dapat dikatakan berjalan dengan baik.

Pengujian kedua dilakukan pada saat LED 2 menyala yang menandakan kWh listrik error atau terjadi peristiwa abnormal yang diberi tanda dengan nyalanya LED kuning pada kWh meter. Ketika sensor photodiode dapat mendeteksi LED kuning tersebut menggunakan ADC dan photodiode berhasil membaca dan mengirimkan sinyal tersebut dan mikrokontroler menerimanya, maka dengan kondisi tersebut mikrokontroler dapat memerintahkan modul GSM untuk mengirim SMS kepada pengguna mengenai terjadinya error atau peristiwa pada $\mathrm{kWh}$ meter pengguna berarti pengujian ini dapat dikatakan berjalan dengan baik. Pengujian ketiga dilakukan

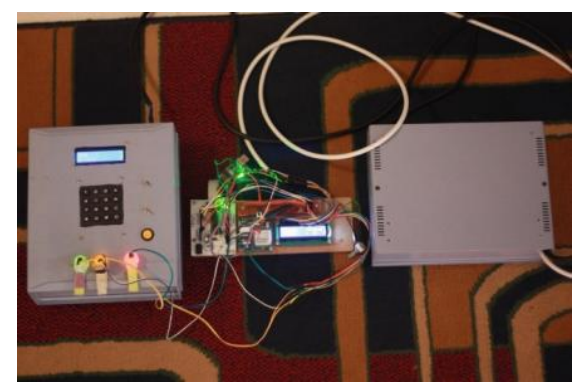

- Gambar 12. Tampilan Keseluruhan Alat Rancangan dan kWh Meter Simulasi 


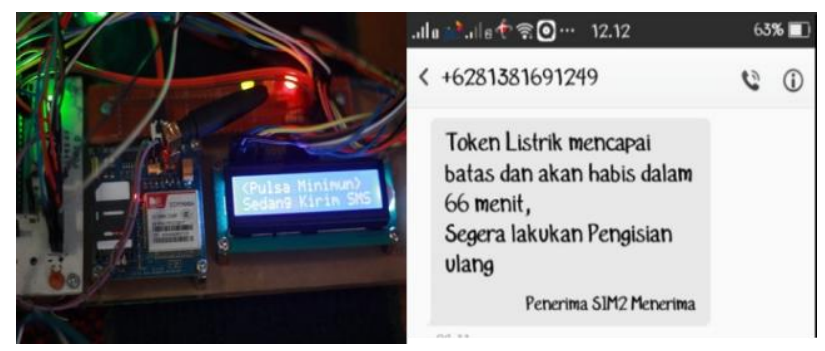

- Gambar 13. Hasil Pendeteksian Alat saat kWh Minimum

pada saat LED 3 aktif atau bekerja yaitu saat perubahan LED 1 dari warna hijau ke merah. LED 3 ini bertugas untuk memberikan informasi mengenai estimasi waktu habisnya pulsa pada kWh meter. LED 3 akan berkedipkedip dan mikrokontroler akan menugaskan sensor photodiode pada indikator LED 3 untuk mendeteksi setiap kedipan-kedipan dari LED 3 tersebut. Sinyal yang ditangkap oleh sensor photodiode dari LED 3 akan dikirim ke mikrokontroler untuk diproses, dimana 1600 kedipan LED 3 tersebut $=1 \mathrm{kWh}$. apabila sensor photodiode dapat mendeteksi 1600 kedipan LED 3 secara benar per kWh sampai pulsa habis lalu sinyal tersebut sampai kepada mikrokontroler sehingga mikrokontroler dapat membacanya setiap kedipan maka mikrokontroler akan menugaskan modul GSM untuk memberi SMS saat kondisi pulsa berada pada 7, 4 dan $1 \mathrm{kWh}$ dan menampilkannya proses di modul LCD serta modul indikator LED sesuai dengan sisa pulsa dan estimasi waktu habisnya pulsa pada $\mathrm{kWh}$ meter sampai kondisi pulsa pada $\mathrm{kWh}$ habis total atau mati.

Berdasarkan dari hasil pengujian secara keseluruhan semua sensor photodiode dapat mendeteksi cahaya indikator LED pada kWh lalu mikrokontroler juga berhasil menugaskan modul-modul lain pada saat kondisi tertentu seperti modul GSM untuk mengirim pesan kepada pengguna mengenai status pulsa, peristiwa abnormal serta estimasi waktu habisnya pulsa ketika sisa pulsa 7, 4 dan $1 \mathrm{kWh}$ pada modul indikator LED untuk melihat pengirimannya dan modul LCD menampilkan kerja sistem dari alat. Pada pengujian dari seluruh sistem ini semua dapat berjalan dengan baik. Berikut ini adalah Tampilan Keseluruhan Alat Rancangan dan kWh Meter Simulasi dapat dilihat pada Gambar 12. Hasil Pendeteksian Alat saat kWh Minimum pada Gambar 13. Hasil Pendeteksian Alat saat Peristiwa Abnormal pada Gambar 14. dan Hasil Pendeteksi Alat saat Menghitung Estimasi Waktu Habisnya Pulsa pada Gambar 15.

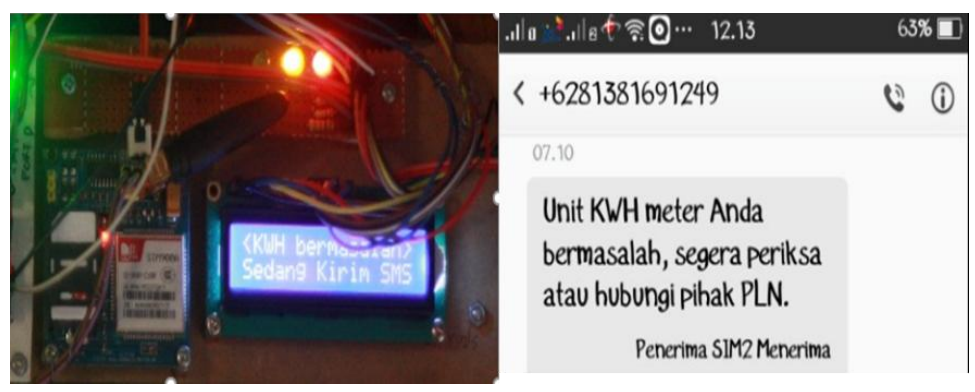

- Gambar 14. Hasil Pendeteksian Alat saat Peristiwa Abnormal

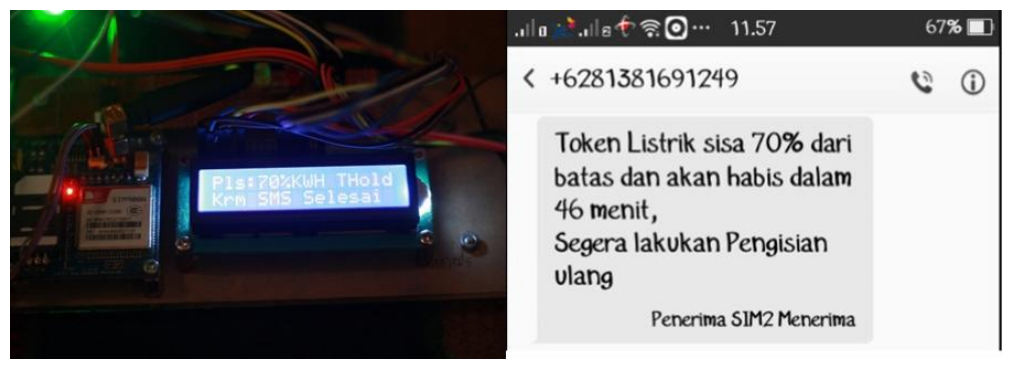

שambar 15. Hasil Pendeteksi Alat saat Menghitung Estimasi Waktu Habisnya Pulsa

\section{KESIMPULAN}

Kesimpulan yang dapat diperoleh dari keseluruhan perancangan sistem monitoring pulsa minimum dan pemberitahuan kerusakan pada kWh meter ini adalah Tampilan indikator LED berwarna merah menandakan alat sedang melakukan proses SMS, LED warna kuning menandakan alat mendeteksi kerusakan pada kWh dan LED warna Hijau menandakan alat mendeteksi kondisi pulsa $\mathrm{kWh}$ telah berada pada kondisi minimum. Perancangan sistem ini akan mengirimkan pemberitahuan SMS mengenai sisa pulsa $\mathrm{kWh}$ pada sisa pulsa 10, 7, 4 dan $1 \mathrm{kWh}$ dan akan memberitahu pengguna apabila terjadi kerusakan atau peristiwa abnormal pada kWh meter. 


\section{DAFTAR PUSTAKA}

[1]. Informasi Keuntungan Listrik Prabayar, Tersedia di www: http://www.pln.co.id/disjaya/?p=4794_5 April 2016)

[2]. Mitsubisi Electric, Panduan Penggunaan KWh Prabayar, Bogor: PT. Melcoinda, 2010, hal 5

[3]. Fitrizawati dan S. Zulkarnain, Analisis Perbandingan Tingkat Kepuasan Pengguna kWh Meter Pascabayar dengan kWh Meter Prabayar, Edisi ke-8. Purwokerto: ITEKS, 2016.

[4]. R. Boylestad and L. Nashelsky, Electronic devices and circuit theory, 7th ed. Englewood Cliffs, N.J.: Prentice-Hall, 1982, p. 783.

[5]. E. Bachtiar, Dasar Mikrokontroler ATMEGA 8535 dengan CAVR, Yogyakarta: Deepublish, 2014, halaman 18-19.

[6]. M. A. Mazidi dan J. G. Mazidi, The 8051 Microcontroller and Embedded Systems, New Jersey: Prentice Hall, 1995, ch10, hal 184-190.

[7]. A. V. Deshmukh, Microcontrollers Theory and Applications. New Delhi: McGraw-Hill, 2005, ch 1, hal 4. 